\title{
Controlling Hard Zone Formation in Friction Stir Processed HSLA Steel
}

\author{
Tracy W. Nelson a and Scott A. Rose ${ }^{\mathbf{b}}$ \\ ${ }^{\text {a }}$ Department of Mechanical Engineering at Brigham Young University, Provo, UT 84602: \\ nelsontw@byu.edu (corresponding author) \\ ${ }^{\mathrm{b}}$ Formerly with Brigham Young University, now with Boeing Research and Technology Metals and \\ Ceramics - Welding Joining and Forming: scott.a.rose4@boeing.com
}

\begin{abstract}
The present study was undertaken to determine the effects of friction stir process conditions on mitigating the "hard zone" often present in FSW HSLA steels. The primary parameters investigated were travel speed, heat input, and cooling rates. The hard zone consists of primarily fine lath ferrite. There are strong linear correlations between the ferrite lath width, hardness of the hard zone, and weld cooling rate. The hard zone was eliminate at cooling rates below $20{ }^{\circ} \mathrm{C} \mathrm{s}^{-1}$ in FSW HSLA-65.
\end{abstract}

Keywords: Friction Stir Welding, HSLA-65, microstructure 


\section{Nomenclature}

$\begin{array}{ll}\text { FSW } & \text { Friction Stir Welding } \\ \text { HSLA } & \text { High Strength Low Alloy } \\ \text { API } & \text { American Petroleum Institute } \\ \text { P } & \text { Power } \\ \text { v } & \text { Travel speed } \\ \text { BM } & \text { Base Metal } \\ \text { RPM } & \text { Revolutions per minute } \\ \text { TMCP } & \text { Thermal Mechanical Controlled Processing } \\ \text { HAZ } & \text { Heat-Affected Zone } \\ \text { CGHAZ } & \text { Course Grain Heat-Affected Zone } \\ \text { PAG } & \text { Prior Austenite Grain } \\ \text { SZ } & \text { Stir Zone } \\ \text { HZ } & \text { Hard Zone } \\ \text { EBSD } & \text { Electron Backscatter Diffraction } \\ \text { HV } & \text { Hardness Vickers } \\ \text { CCT } & \text { Continuous Cooling Transformation }\end{array}$

\section{INTRODUCTION}

Friction stir welding is a solid-state joining process. The lower peak temperatures associated with FSW create less degradation to the carefully controlled microstructures in higher strength HSLA steels. As a result, post-weld properties in friction stir welds in steels often exceed that of arc welds.

An area of concern in FSW HSLA steels is a region of high hardness that persists in the weld nugget. This "hard zone" is generally localized on the advancing side of the weld nugget, 
but as Tribe et al. (2015) showed, it can grow to consume a significant portion of the weld nugget depending on the weld parameters. Nelson et al. (2007) show that the hard zone consists of fine lath ferrite while the rest of the weld nugget can consist of coarse lath ferrite or polygonal ferrite.

This hard zone has been reported in various alloys and over a wide range of welding parameters. Table 1 highlights some of the alloys, hardness values, and welding parameters where the hard zone has occurred. The hard zone region was observed to be 10 to $40 \%$ higher than the rest of the weld with the difference in hardness increasing with increased alloy strength.

Table 1. Hard zone characteristics and parameters.

\begin{tabular}{ccccccc}
\hline $\begin{array}{c}\text { Steel } \\
\text { Alloy }\end{array}$ & $\begin{array}{c}\text { Average } \\
\text { Weld } \\
\text { Hardness } \\
\text { (HV) }\end{array}$ & $\begin{array}{c}\text { Peak } \\
\text { Hardness } \\
(\text { HV })\end{array}$ & $\begin{array}{c}\text { Difference } \\
(\text { HV })\end{array}$ & $\begin{array}{c}\text { Rotational } \\
\text { Speed (RPM) }\end{array}$ & $\begin{array}{c}\text { Travel Speed } \\
(\mathrm{mm} \text { min-1 })\end{array}$ & Source \\
\hline 1018 & 160 & 175 & 15 & $450-650$ & $25-100$ & Lienert, et al., 2003 \\
X65 & 220 & 280 & 60 & 350,550 & 75,175 & Nelson, et al., 2007 \\
X80 & 250 & 350 & 100 & 550 & 100 & Ozekcin, et al., 2004 \\
L80 & 400 & 500 & 100 & 450,550 & 100 & Nelson, et al., 2007
\end{tabular}

This hard zone has been shown to have lower fracture toughness than the rest of the weld and heat-affected zone (HAZ). Tribe et al. (2015) reported that minimum CTOD values were sensitive to location within the weld nugget in API X-80. They reported direct correlations between the minimum CTOD values and the fraction of hard zone contained along the crack front.

Several investigators have postulated reasons for the presence of the hard zone in FSW HSLA steels. Ozekcin et al. (2004) suggested that the high hardness is a result of high peak temperatures causing austenite grain coarsening followed by faster cooling rates. They estimated temperatures in the weld to exceed the A3 based on post-weld microstructures. Since they only ran one set of weld parameters in both X-80 and L-80 steels it is difficult to evaluate the effects of peak temperature and cooling rate. Nelson et al. (2007) reported that the hard zone occurred 
in welds run at higher heat input. Although reported, there were no analyses to develop correlations between these.

Some studies have used physical weld simulations, such as hot compression and hot torsion tests, to investigate the effects that strain, strain rate, peak temperature, and cooling rate have on the weld microstructure. Matsushita et al. (2011) varied the peak temperature, strain, and strain rate while holding the cooling rate constant in hot compression samples. They found that the strain and strain rate had a negligible effect on the microstructure and suggested that the thermal effects had a much larger influence on the microstructure. Allred (2012) varied peak temperature, strain rate, and cooling rate in hot torsion tests. He also reported that that the microstructure was primarily the result of cooling rate. The findings of Matsushita and Allred suggest that in order to control the microstructure in FSW, control over the peak temperature and cooling rate are needed.

There have been no investigations that have attempted to control or mitigate the hard zone in FSW HSLA steels. The purpose of this study was to investigate the effects of FSW parameters, including weld cooling rate, on the hard zone of HSLA-65 steel.

\section{EXPERIMENTAL APPROACH}

\section{$2.1 \quad$ Weld Setup}

All welds in this study were bead-on-plate welds performed on a MTI model RM2 FSW machine using a polycrystalline cubic boron nitride $(\mathrm{PCBN})$ convex scrolled shoulder step spiral (CS4) tool (model E44111). Welds were run in separate $6.35 \mathrm{~mm}$ thick HSLA-65 plates. Each plate was ground on both sides to remove the mill scale. Each weld was $750 \mathrm{~mm}$ in length.

Tool temperature data was obtained from a K-type thermocouple inserted into the tool

collar. Plate temperatures were obtained from K-type thermocouples placed in the weld plate at a depth of $3.8 \mathrm{~mm}$ from the surface of the plate. The thermocouples were positioned in the HAZ at three different distances from the weld center: $4.6 \mathrm{~mm}, 6.1 \mathrm{~mm}$ and $7.6 \mathrm{~mm}$. Each position 
was replicated three times within a given weld. Their linear positions were randomized to prevent other variables from potentially skewing the results.

A central composite face centered design $(\mathrm{CCF})$ of 10 runs was developed using backing plate material and heat input as the factors. The response variables used in this study were cooling rate and 95th percentile hardness. A least squares analysis was performed for each response variable followed by an analysis of variance test in $\mathrm{JMP}^{1}$.

The numerical values for the backing plate levels were the logarithm of the thermal conductivity. Thermal diffusivity is generally used when dealing with transient systems. However, analysis of the thermal conductivities and diffusivities of each of the backing plates used showed a linear correlation between the two properties. Thermal conductivity is the more commonly reported of the material thermal properties; thermal conductivity was used in the present study.

The heat input levels were determined using three evenly spaced power and travel speed levels, thus confounding power and travel speed with the heat input. The properties for each factor are listed in Table 2.

Table 2. Factor levels of final design of experiments

\begin{tabular}{cccc|cccc}
\hline \multicolumn{3}{c|}{ Backing Plate Variables } & \multicolumn{3}{c}{ Heat Input Variables } \\
\hline Level & Material & $\begin{array}{c}\mathrm{k} \\
\left(\mathrm{W} \mathrm{m}^{-1} \mathrm{~K}^{-1}\right)\end{array}$ & $\log \mathrm{k}$ & $\begin{array}{c}\text { Power } \\
(\mathrm{W})\end{array}$ & $\begin{array}{c}\text { Travel } \\
\left(\mathrm{mm} \mathrm{min}^{-1}\right. \\
\left.[\mathrm{in} \mathrm{min})^{-1}\right)\end{array}$ & $\begin{array}{c}\text { Heat Input } \\
\left(\mathrm{J} \mathrm{mm}^{-1}\right)\end{array}$ & $\begin{array}{c}\text { Heat Input } \\
\text { Level }\end{array}$ \\
\hline-1 & Granite & 2.7 & 0.4314 & 3750 & $76(3)$ & 2953 & 1.5 \\
0 & AL6XN & 11.8 & 1.0719 & 4500 & $152(6)$ & 1772 & 0 \\
1 & Steel & 51.9 & 1.7152 & 5250 & $229(9)$ & 1378 & -0.5
\end{tabular}

The temperatures for all of the embedded thermocouples exceeded the $\mathrm{A}_{3}$ temperature. Thermal cycle data were processed to calculate the HAZ cooling rate from 800 to $500{ }^{\circ} \mathrm{C}$. The magnitudes of the cooling rates stayed fairly constant for each thermocouple position.

\footnotetext{
${ }^{1} \mathrm{JMP}$ is a statistical discovery software from SAS: www.jmp.com
} 
Therefore, the cooling rates acquired from all the thermocouples in a weld were averaged together to give a single cooling rate per weld.

Samples for metallographic and electron backscatter diffraction analysis (EBSD) were removed from each weld. Metallographic samples were ground and polished to a $1 \mu \mathrm{m}$ finish according to standard practices and etched with $2 \%$ Nital. Microhardness measurements were taken across each sample using a Vickers hardness indenter at $500 \mathrm{~g}$ and $0.3 \mathrm{~mm}$ grid spacing. EBSD samples were polished through $0.5 \mathrm{~mm}$ using colloidal Silica. Several lath measurements were taken across the EBSD images and were averaged together to yield a single lath width and length value for each weld.

In order to study the heterogeneity in the weld nugget of FSW HSLA steels, it was necessary to establish a quantitative measure. In this study, the hard zone is characterized by a $95^{\text {th }}$ percentile hardness value. The $95^{\text {th }}$ percentile hardness metric was obtained by a percentile ranking of the hardness data for each weld. The $\mathrm{N}$ number of hardness values for each hardness map was ranked from lowest to highest hardness. The ranking excludes 0 and $100 \%$ such that the first and last points are assigned the percentile $1 / 2 \mathrm{~N}$ and $1-1 / 2 \mathrm{~N}$ respectively. This is done to allow for the case that the true maximum and minimum hardness of each weld are not captured during the microhardness testing. Each interior point of the ranking increased in rank at a rate of $1 / \mathrm{N}$.

A rough delineation also had to be made between weld metal and base metal for purposes of calculating the average weld hardness. The $50^{\text {th }}$ percentile hardness for all specimens was $210 \pm 4 \mathrm{HV}$. This value proved to be a good approximation of the weld outline upon examination of the weld hardness maps. Thus all values above $210 \mathrm{HV}$ in each metallographic sample were included in the calculation of the average weld hardness.

\section{RESULTS AND DISCUSSION}

Using this metric, the hardness value at the $95^{\text {th }}$ percentile point is used to represent the hard zone hardness. The $95^{\text {th }}$ percentile hardness values at each of the parameter levels used in this study are listed in Table 3. 
Table 3. Measured $95^{\text {th }}$ percentile hardness at each backing plate and heat input level.

\begin{tabular}{cccc}
\cline { 2 - 4 } & \multicolumn{3}{c}{$95^{\text {th }} \begin{array}{c}\text { percentile Hardness } \\
(\mathrm{HV})\end{array}$} \\
\hline Heat Input & \multicolumn{3}{c}{ Backing Plate Material } \\
\cline { 2 - 4 }$\left(\mathrm{J} \mathrm{mm}^{-1}\right)$ & Granite & AL6XN & Steel \\
\hline 1378 & 264 & 280 & 298 \\
1772 & 242 & $266^{*}$ & 279 \\
2953 & 234 & 263 & 272 \\
*Center point hardness values are averaged
\end{tabular}

In order to better understand the effects of process parameters on the hard zone, the 95th percentile hardness was evaluated against different weld process parameters. The 95th percentile hardness values are plotted against heat input in Figure 1. 95th percentile hardness from all welds exhibits a very poor correlation $\left(\mathrm{R}^{2}=0.2196\right)$ with heat input (black line fit to all data). If the data are grouped and fitted by the individual backing plate material (indicated by the dashed lines in Figure 1) the fit is better (0.4709 to 0.7344$)$ than that of the heat input, but neither capture the trends well. Similar results were reported by Wei and Nelson (2012) in that postweld properties and microstructure correlated best with weld heat input compared to other weld parameters and heat indexes, but the correlation was not particularly strong.

It is well established that microstructure and properties in steels are highly dependent on cooling rate from the austenitic temperature range. Given that: 1) the data in Figure 1 correlates better with the backing plate material than heat input, and 2) the backing plate material will have a strong influence on the cooling rate, the 95th percentile hardness was evaluated against the cooling rate.

The HAZ cooling rate for each weld at the different parameter levels used in this study is listed in Table 4. Figure 2 shows the 95th percentile hardness data plotted against cooling rate. Unlike the trends in Figure 1, there is a strong linear relationship between 95th percentile hardness and cooling rate (Figure 2). The curve fit of Figure 2 shows that this relationship encompasses all of the weld data $\left(\mathrm{R}^{2}=0.9466\right)$ accounting for all but $5.4 \%$ of the variation. 


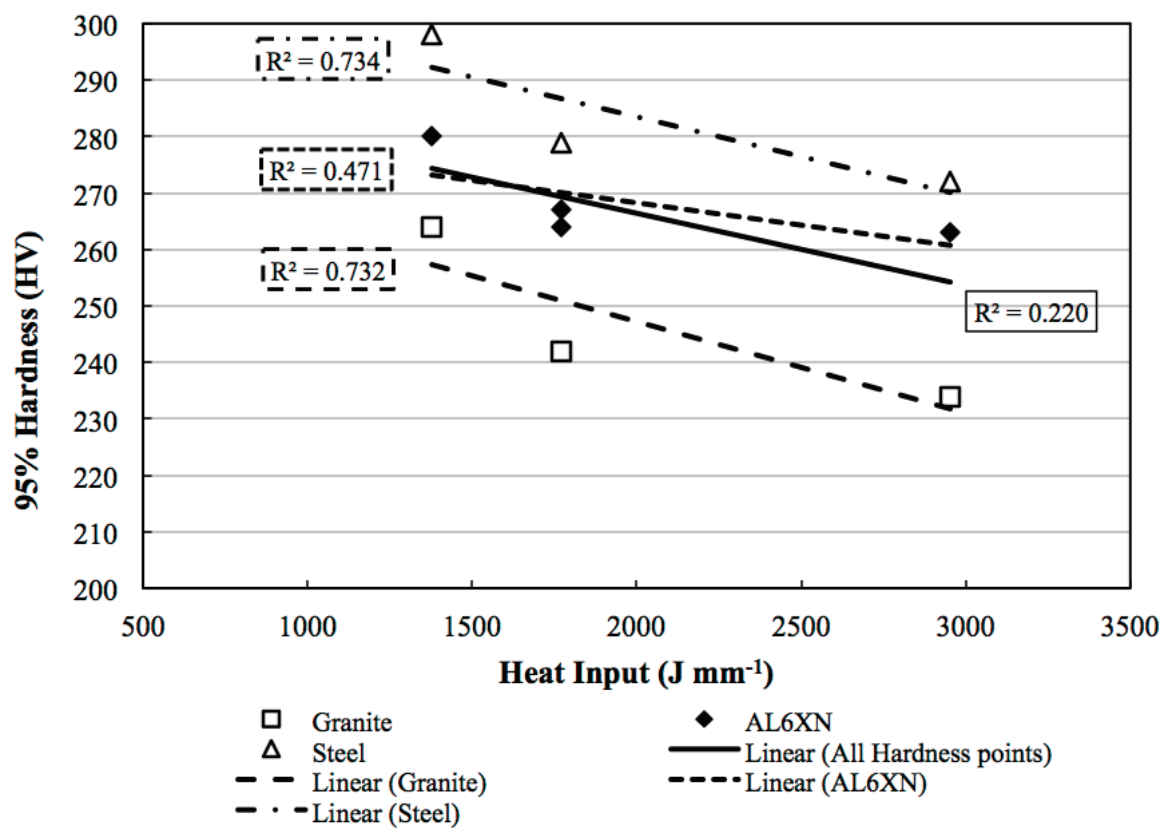

Figure 1. 95th percentile hardness plotted against heat input.

Table 4. Measured cooling rate at each backing plate and heat input level.

\begin{tabular}{cccc} 
& \multicolumn{3}{c}{ HAZ Cooling Rate $\left({ }^{\circ} \mathrm{C} \mathrm{s}^{-1}\right)$} \\
\hline \multirow{2}{*}{$\begin{array}{c}\text { Heat Input } \\
\left(\mathrm{J} \mathrm{mm}^{-1}\right)\end{array}$} & \multicolumn{3}{c}{ Backing Plate Material } \\
\cline { 2 - 4 } & Granite & AL6XN & Steel \\
\hline 1378 & 15.4 & 21.4 & 29.7 \\
1772 & 9.3 & $16.8^{*}$ & 21.9 \\
2953 & 7 & 14.5 & 15.6
\end{tabular}

*Center point cooling rates are averaged 


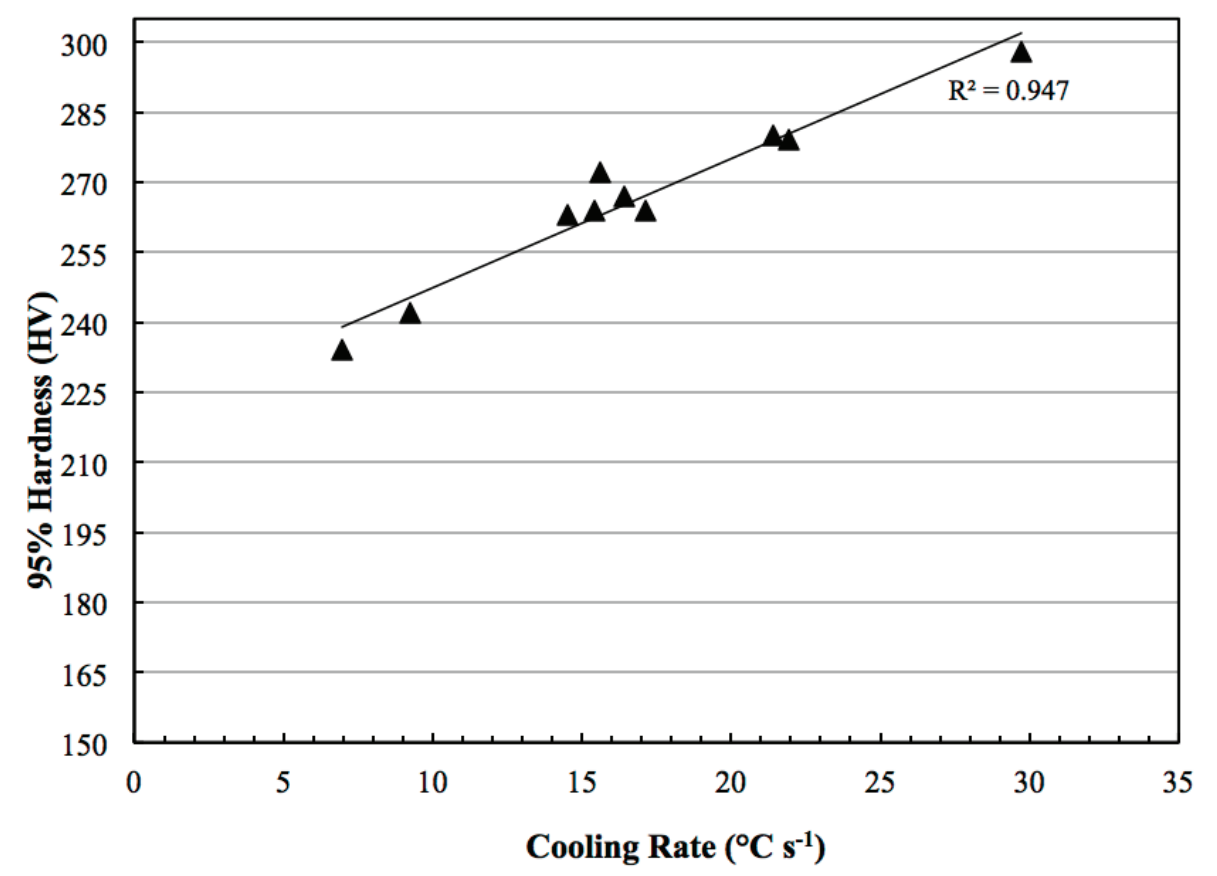

Figure 2. 95th percentile hardness plotted against HAZ cooling rate.

The relationship between hardness and cooling rate is not limited to the 95th percentile hardness. A comparison between the cooling rate and other hardness characteristics is found in Table 5. Each of the measured hardness characteristics increases with increasing cooling rate. Assuming that the weld temperature exceeds the $\mathrm{A}_{3}$, post-weld hardness of the weld nugget and hard zone in FSW HSLA65 are predominately a function of cooling rate.

Table 5. Hardness characteristics for the different cooling rate ranges.

\begin{tabular}{ccccc}
\hline Cooling Rate & $\begin{array}{c}\text { Average Weld } \\
\text { Hardness (HV) }\end{array}$ & $\begin{array}{c}\text { 95th percentile } \\
\text { Hardness (HV) }\end{array}$ & $\begin{array}{c}\text { Difference } \\
(\mathrm{HV})\end{array}$ & \% Difference \\
\hline$<10^{\circ} \mathrm{C} \mathrm{s}^{-1}$ & 225 & 238 & 13 & $6 \%$ \\
$16^{\circ} \mathrm{C} \mathrm{s}^{-1}$ & 243 & 266 & 23 & $9 \%$ \\
$22^{\circ} \mathrm{C} \mathrm{s}^{-1}$ & 251 & 280 & 28 & $11 \%$ \\
$30^{\circ} \mathrm{C} \mathrm{s}^{-1}$ & 260 & 298 & 38 & $14 \%$
\end{tabular}

In Figure 3, a hardness map of each weld is overlaid on a plot of heat input versus cooling rate. The maps and cooling rate values are grouped by backing plate material. Each 
hardness map is identified by the acronym of that weld's backing plate material and heat input level. For example, the weld on granite $(\mathrm{G})$ with the highest $(\mathrm{H})$ heat input is labelled $\mathrm{GH}$.

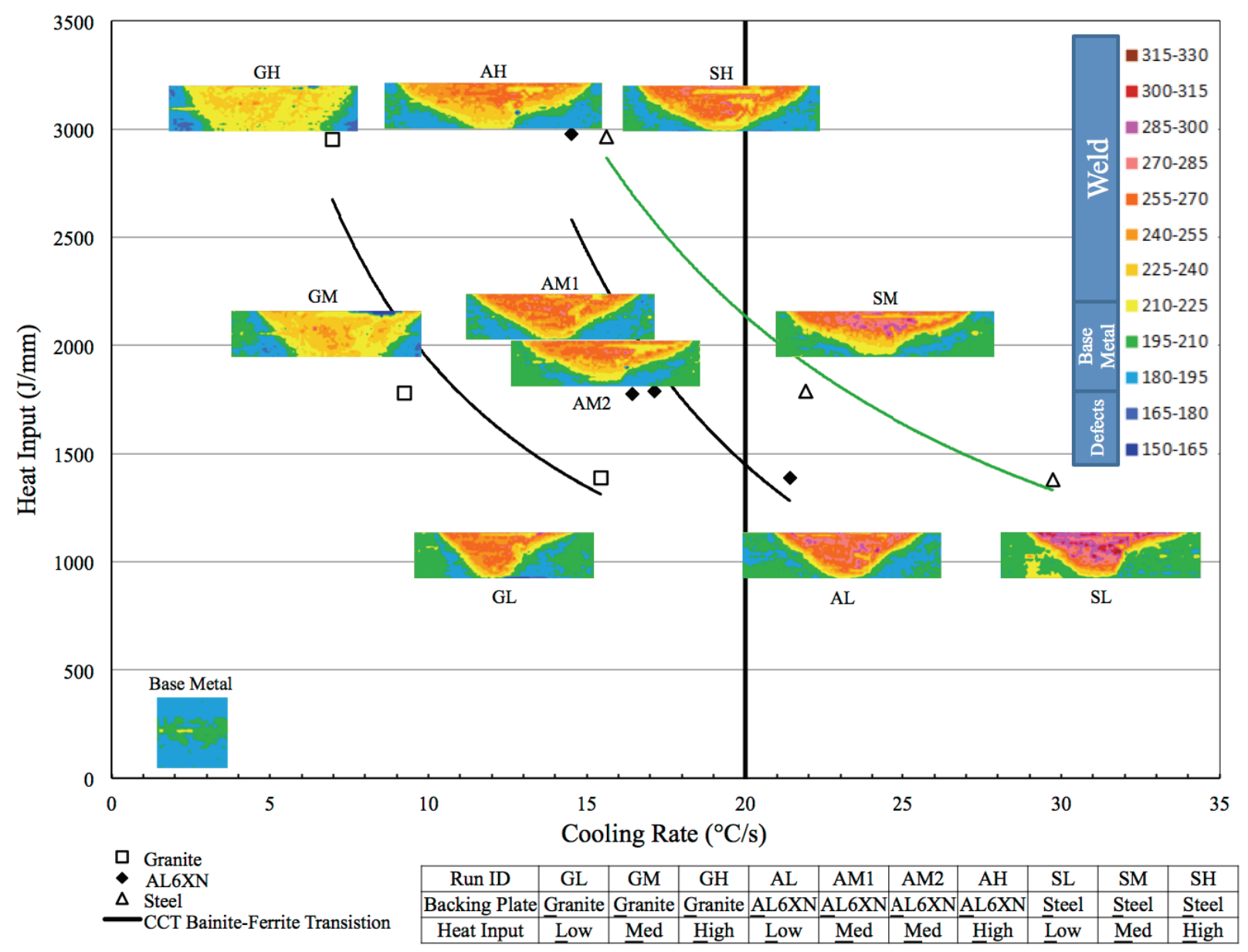

Figure 3. Hardness maps (HV) of each run plotted by heat input and cooling rate.

Comparing all of the hardness maps, there are significant differences in peak hardness among the various welds, as well as variation in the hardness within a given weld across the parameters studied. Above $20^{\circ} \mathrm{C} \mathrm{s}^{-1}$, the welds exhibit higher peak hardness and greater differences between peak and average hardness (AL, SM, SL). Below $20{ }^{\circ} \mathrm{C} \mathrm{s}^{-1}$, welds are more uniform, exhibiting lower peak hardness and the hard zone is effectively eliminated (GH and GM). At cooling rates near $16^{\circ} \mathrm{C} \mathrm{s}^{-1}$, there are five welds of similar cooling rate (SH, AH, AM1, AM2, GL) which, despite the differences in backing plate and heat input level, exhibit very similar hardness maps (both peak hardness, and 95th percentile hardness). 
The present study was able to produce numerous welds without a hard zone by incorporating the use of different backing plate materials. Although welds of the same heat input were run on each backing plate, those run on AL6XN and granite had lower cooling rates which resulted in greater uniformity in hardness, effectively eliminating the hard zone in the weld nugget (Figure 3 and Table 5). If we define a lower bound of the hard zone as a minimum 10\% difference in hardness between the 95th percentile hardness value and the average weld hardness (Table 2), based on the data in Table 5 and Figure 3, HAZ cooling rates less than $20^{\circ} \mathrm{C} \mathrm{s}^{-1}$ are required to achieve more uniform hardness and avoid the formation of the hard zone. This was achievable at nearly all parameters on backing plates of low thermal conductivity (AL6XN and granite). On a steel backing plate this is only achievable at very high heat inputs, i.e. very low travels speeds.

If post-weld cooling rate is the dominant factor, then other microstructure characteristics should also correlate very well with cooling rate. A CCT diagram of X-65 is shown in Figure 4 (Endo et al., 2002). The cooling rates of four welds (SH, SL, GH, Figure 3) have been superimposed on the CCT diagram in Figure 4 and the OIM ${ }^{\mathrm{TM}}$ grain maps from the hard zone region of these same welds are shown in Figure 5. This CCT diagram indicates that at cooling rates less than $20^{\circ} \mathrm{C} \mathrm{s}^{-1}$ the microstructure should consist of polygonal and Bainite.

The microstructure of the $\mathrm{GH}$ weld $\left(7^{\circ} \mathrm{C} \mathrm{s}^{-1}\right)$ contains grain boundary and polygonal ferrite, and coarse lath ferrite (Figure 5a). The SH (Figure 5b) and GL (Figure 5c) welds which had average cooling rates of $16^{\circ} \mathrm{C} \mathrm{s}^{-1}$ consist of primarily fine lath ferrite and some grain boundary ferrite. There is a notable difference in lath length in these two welds (SH and GL): this will be presented and discussed below. It should be noted that all post-weld microstructures in the present study exhibited a lath (high length-to-width aspect ratio) morphology. It is not the objective of this paper to identify or differentiate the individual microstructures i.e. lath martensite, lath bainite, granular bainite, acicular ferrite or Widmanstätten ferrite, for each weld 
condition. The authors used the term "lath" throughout the paper to describe the morphology of the post-weld microstructures rather than the specific phase.

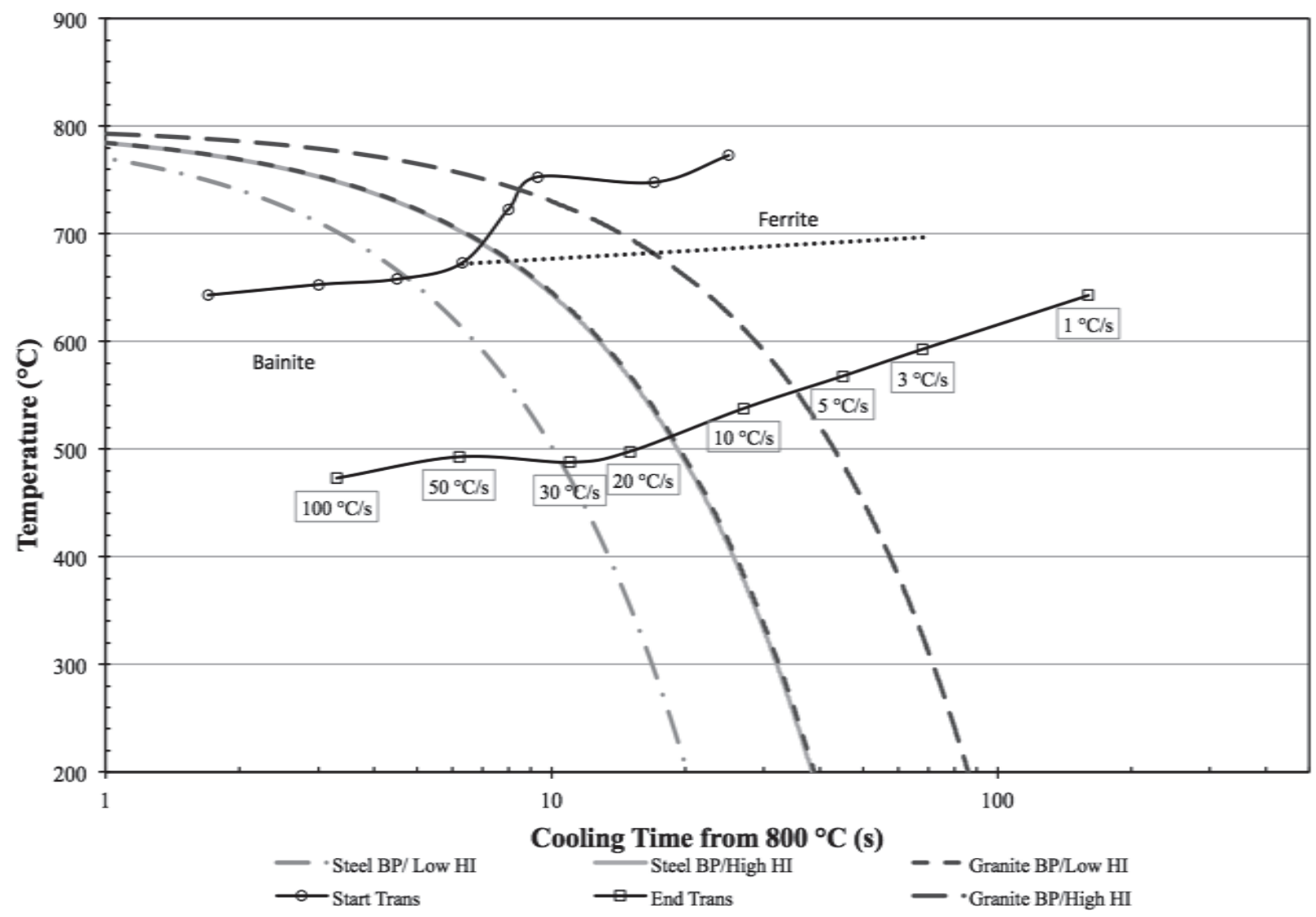

Figure 4. CCT diagram for X-65 with four HAZ cooling rates. (Endo, et.al, 2002)

At cooling rates greater than $20^{\circ} \mathrm{C} \mathrm{s}^{-1}$, the microstructure should primarily consist of fine lath ferrite or bainite (Figure 4). Figure 5d shows the grain map for the SL weld that had a HAZ cooling rate of $30^{\circ} \mathrm{C} \mathrm{s}^{-1}$. The microstructure consists of fine lath ferrite or bainite.

The formation of bainite at cooling rates greater than $20^{\circ} \mathrm{C} \mathrm{s}^{-1}$ correlates with the presence of the hard zone above this critical cooling rate (Figure 3). Therefore, the hard zone observed in FSW HSLA steels is primarily the result of faster cooling rates, which produces fine lath (martensite and or Bainite) microstructures. 


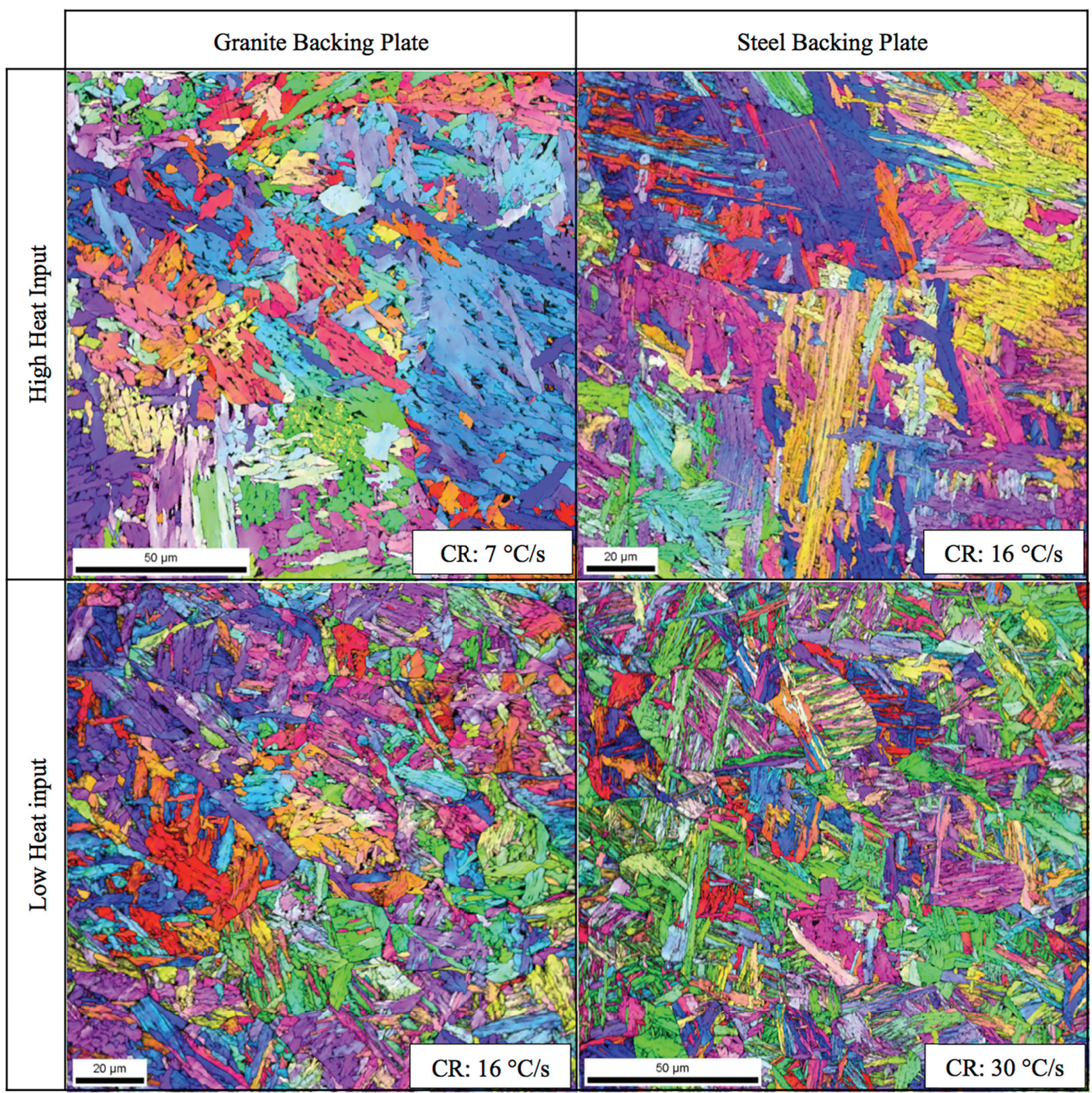

Figure 5. EBSD images of four weld hard zones: a) granite-high heat input, b) steel-high heat input, c) granite-low heat input, and d) steel-low heat input.

It is appears that heat input and backing plate material have an effect on both lath length and width (Figure 5). The lath length and width of each weld in Figure 5 were measured quantitatively using the method presented by Wei and Nelson (2012). These data are shown in Table 6. The average lath lengths are plotted against the heat input in Figure 6. Lath length increases with increasing heat input regardless of the backing plate material: an average increase 
of $13.9 \mu \mathrm{m}$ occurred with an increase in heat input of $1570 \mathrm{~J} \mathrm{~mm}^{-1}$. The longer laths in the higher heat input welds are likely the result of larger prior austenite grain size, which is consistent with previous work (Ozekcin et al, 2004: Wei and Nelson, 2012). Additionally, the lath lengths were nearly identical at the same heat inputs regardless of the backing plate material. This indicates that cooling rate has little effect on the lath length.

Table 6. Average lath width and length as a function of backing plate and heat input.

\begin{tabular}{ccccc}
\cline { 2 - 5 } & \multicolumn{2}{c}{ Lath Width $(\mu \mathrm{m})$} & \multicolumn{2}{c}{ Lath Length $(\mu \mathrm{m})$} \\
\hline \multirow{2}{*}{$\begin{array}{c}\text { Heat Input } \\
\left(\mathrm{J} \mathrm{mm}^{-1}\right)\end{array}$} & \multicolumn{2}{c}{ Backing Plate } & \multicolumn{2}{c}{ Backing Plate } \\
\cline { 2 - 5 } & Granite & Steel & Granite & Steel \\
\hline 1378 & 0.9 & 0.6 & 20 & 22.3 \\
2953 & 1.1 & 0.8 & 34.5 & 35.5
\end{tabular}

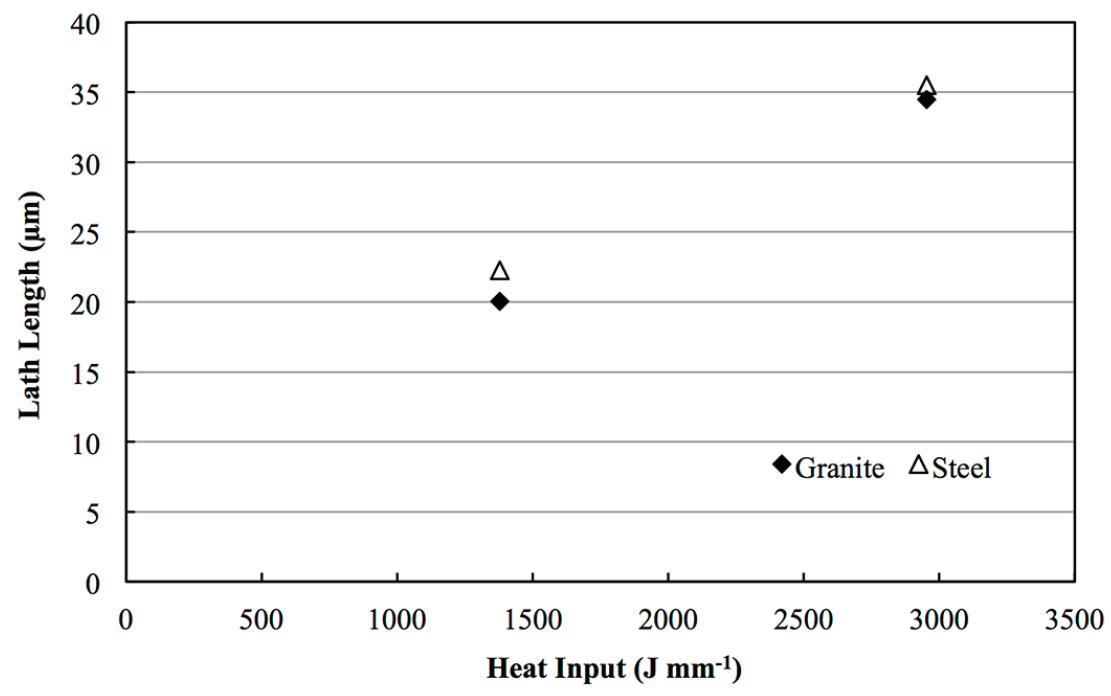

Figure 6. Average lath length versus heat input.

From the data in Table 6, both backing plate material and heat input had a significant effect on lath width. Over the range of heat inputs investigated, the change in lath widths were roughly $21 \%$ and $27 \%$ on the granite and steels backing plates, respectively. At a fixed heat input, the change in lath width was roughly $30 \%$ when changing the backing plate from granite 
to steel. Combining the effects of both heat input and backing plate material, the maximum change in lath width was nearly double, from 0.6 to $1.1 \mu \mathrm{m}$.

Both the backing plate materials and heat input affect the weld cooling rate. The average lath width is plotted as a function of the HAZ cooling rate in Figure 7. There is a strong linear relationship between cooling rate and lath width: decreasing lath width with increasing cooling rate. In welds having roughly the same cooling rate, the difference in lath width is very small. The GL and $\mathrm{SH}$ welds both have cooling rates of roughly $16^{\circ} \mathrm{C} \mathrm{s}^{-1}$ (indicated by the circle in Figure 7). The difference in lath width between these two welds is $0.07 \mu \mathrm{m}$.

Figure 8 shows the 95th percentile hardness values versus lath width. There is a very strong correlation between 95th percentile hardness and lath width.

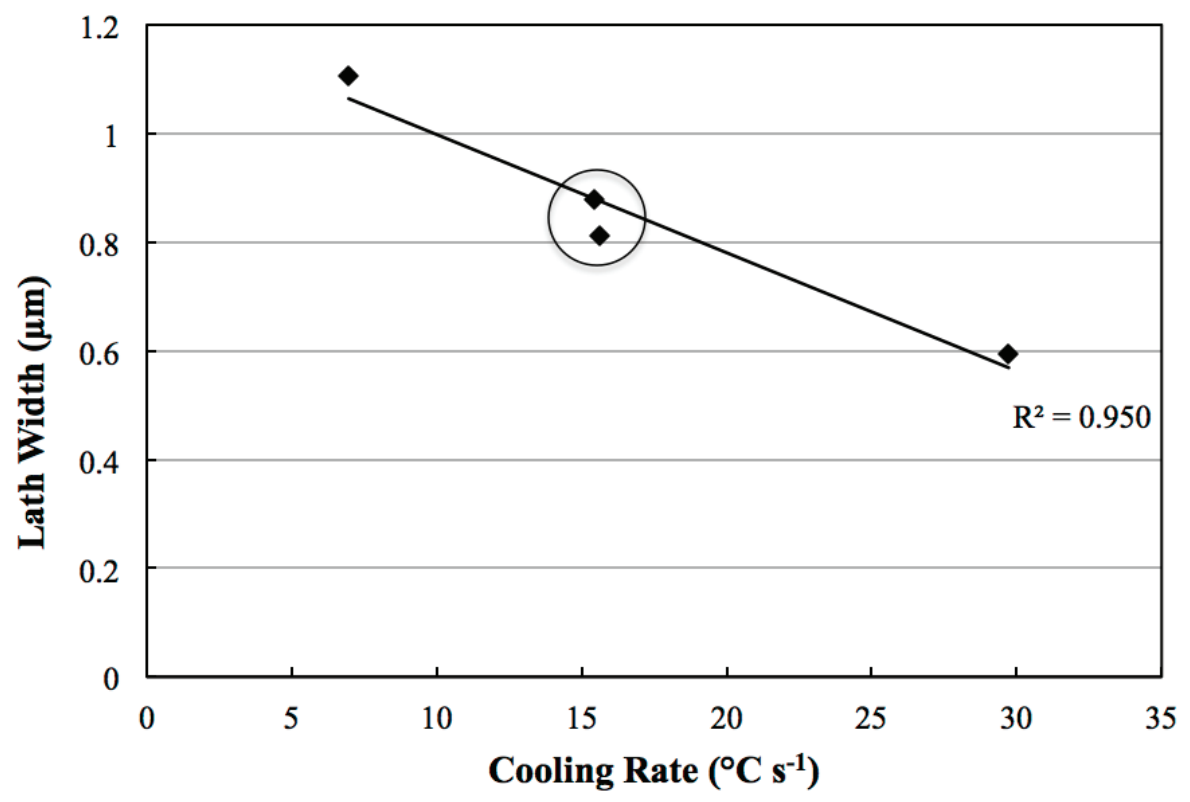

Figure 7. Average lath width by cooling rate. 


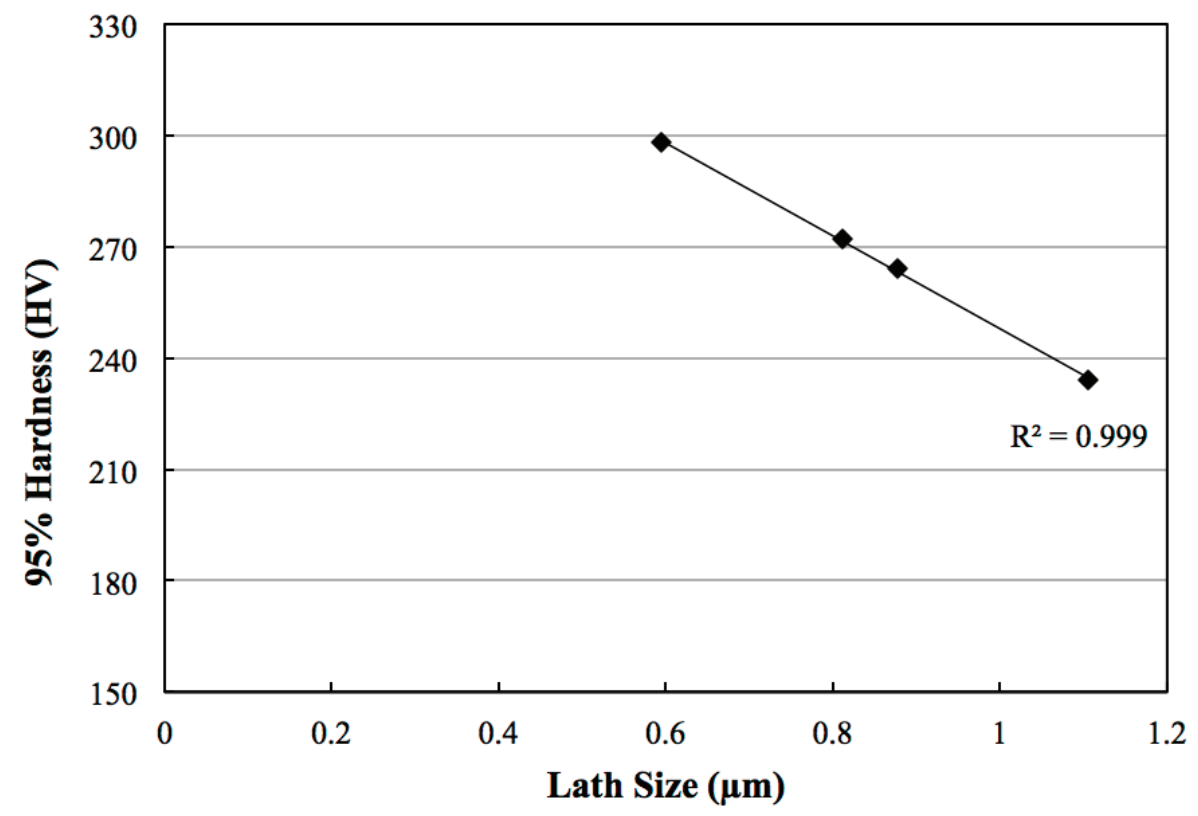

Figure 8. Hard zone hardness by average lath width.

Despite the serve elevated temperature deformation occurring during the FSW process, post-weld cooling rate is the primary factor governing post-weld microstructures and properties in FSW HSLA steels. There are strong linear correlations between weld cooling rate and both post-weld lath width and 95th percentile hardness. These results are consistent with Allred (2013) and Matsushita's (2011) findings using physical weld simulations: both reported that cooling rate dominated the simulated microstructure.

Traditionally, cooling rate has not been used as a control parameter in FSW. Cooling rate has been an outcome that varies as a result of changes to the travel and rotational speeds, tool depth, etc., on a fixed backing plate. This approach produces a limited range of cooling rates. In the present study, the range of cooling rates achieved by changes in heat input alone on a steel backing plate was $14^{\circ} \mathrm{C} \mathrm{s}^{-1}$ (Table 4). Additionally, there is a very limited range of heat input that will produce cooling rate less than $20^{\circ} \mathrm{C} \mathrm{s}^{-1}$ on a steel anvil (Figure 3). This makes it difficult to avoid the presence of the hard zone unless welds are run at very high heat inputs, i.e. low travel speeds. 
Of the data reported in the literature on FSW of steels, all previous investigators have used a steel-backing anvil. Based on the parameters reported in these, the current authors estimate that most, if not all, previous studies have been run at parameters that would produce cooling rates greater than $20^{\circ} \mathrm{C} \mathrm{s}^{-1}$ (steel anvil and travels speeds greater than $1.25 \mathrm{~mm} \mathrm{~s}^{-1}$ ). This would explain the prevalence of heterogeneity in hardness (or presence of a hard zone) in the weld nugget of FSW in the different steels reported in the literature.

Combining the effects of both the backing plate and the heat input effectively enlarges the FSW process window. Cooling rates as low as $7^{\circ} \mathrm{C} \mathrm{s}^{-1}$ were possible on the granite backing plate compared to $15^{\circ} \mathrm{C} \mathrm{s}^{-1}$ on the steel backing plate. This may not seem significant, but it was sufficient to eliminate the hard zone often reported in FSW HSLA steels. Additional benefits include:

1) the ability to reduce the cooling rate at a given heat input. This would be beneficial when productivity is important: high travel speeds are desired. A backing plate of lower thermal conductivity can be used to reduce or eliminate heterogeneity in the weld nugget.

2) the ability to achieve the same cooling rate over a range of heat inputs (indicated by the highlighted region in Figure 9). This enables some variability in parameters (in this study the travel speed was tripled) while maintaining similar microstructure (Figure 5) and properties (Figure 2, Table 4).

The use of the backing plate as an additional process variable in FSW may enable greater weld productivity with the ability to have more control over post-weld properties by controlling post-weld cooling rate. Pre-heat is another method that could be used to achieve similar results. 


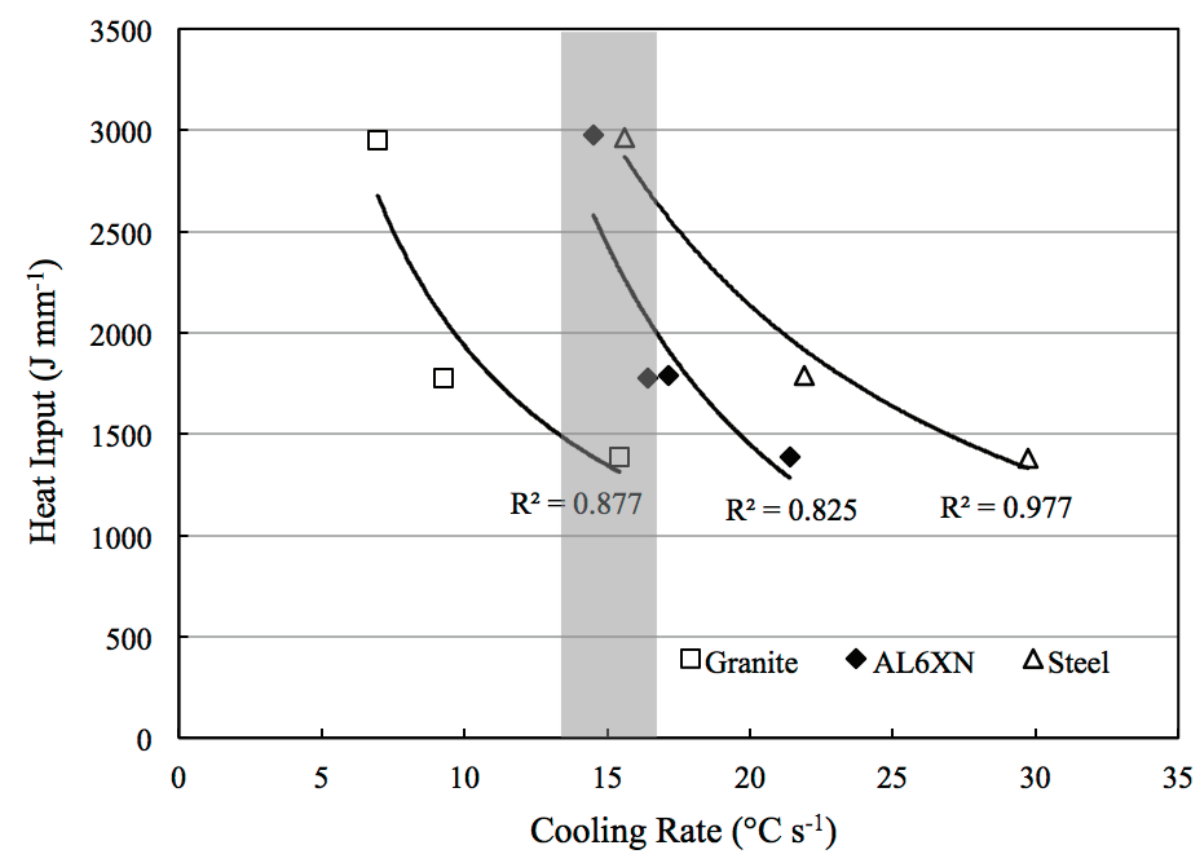

Figure 9. Cooling rate vs heat input by backing plate material.

\section{CONCLUSIONS}

The hard zone reported in FSW of HSLA steels was previously believed to be the result of high peak temperatures or high heat inputs. Rotational and travel speed were used as the primary process parameters in most of the previous work in FSW of steels. In this study, heat input and backing plate material were used as the primary control variables to study the effects of process variables on the evolution of microstructure in FSW HSLA steel. The following conclusions can be made:

- Post-weld cooling rate is the dominant factor affecting weld nugget microstructures in FSW HSLA steels over the range of parameters investigated.

- The hard zone in FSW HSLA 65 was eliminated at HAZ cooling rates below $20^{\circ} \mathrm{C} \mathrm{s}^{-1}$.

- A two-fold change in cooling rate was achievable as a result of changing the anvil material from granite to steel at any given level of heat input. 
- The lath width decreased linearly with increasing cooling rate, from $1.11 \mu \mathrm{m}$ at $7{ }^{\circ} \mathrm{C} \mathrm{s}^{-1}$ to $0.59 \mu \mathrm{m}$ at $30^{\circ} \mathrm{C} \mathrm{s}^{-1}$. This caused a linear increase in hard zone hardness, from 234 to $298 \mathrm{HV}$.

- Lath length was proportional to heat input regardless of the backing plate material: increasing an average of $14 \mu \mathrm{m}$ over the range of heat inputs investigated.

\section{ACKNOWLEDGMENTS}

Funding for this work was provided by the National Science Foundation's Industry/ University Cooperative Research Center Program and the Center for Friction Stir Processing under grant number IIP-0934377.

\section{REFERENCES}

Allred, J., 2013. An investigation into the mechanisms of formation of the hard zone in FSW X65. Department of Mechanical Engineering, Brigham Young University, Provo, UT (M.S. thesis).

Endo, S., Ishikawa, N., Kondo, J., Suzuki, N., Omata, K., 2002. Advance in high performance linepipes with respect to strength and deformability. In Proc. of the Int. Conf. Pipe Dreamer's Conference, Yokohama, Japan, pp. 7-8.

Lienert, T.J., Stellwag, W.L., Grimmett, B.B., Warke, R.W., 2003. Friction stir welding studies on mild steel. Weld. Jour. 82(1), 1-9 S.

Matsushita, M., Kitani, Y., Ikeda, R., Endo, S., 2011. Microstructure and toughness of friction stir weld of $12 \mathrm{~mm}$ thick structural steel. Twenty-first International Offshore and Polar Engineering Conference, Maui, Hawaii, June 19-24, 506-513.

Nelson, T.W., Anderson, S.J., Segrera, D.J., 2007, Friction stir welding of X-65 steel. Friction Stir Welding and Processing IV, TMS Annual Meeting, Orlando, FL, ISBN 978-0-87339661-5, 269-277.

Ozekcin, A., Jin, H.W., Koo, J.Y., Bangaru, N.V., Ayer, R., Vaughn, G., Steel, R., Packer, S., 2004. A microstructural study of friction stir welded joints of carbon steels. International Proceedings of The Fourteenth International Offshore and Polar Engineering Conference, 2328 May, Toulon, France.

Tribe, A., Nelson, T.W., 2012. Study on the fracture toughness of friction stir welded API X80. Journal of Engineering Fracture Mechanics, currently under reision.

Wei, L., Nelson, T.W., 2012. Influence of heat input on post weld microstructure and mechanical properties of friction stir welded HSLA-65 steel. Mater. Sci. Eng. A 556, 51-59. 